A successful pharmaceutical industry is fuelled by a continued flow of graduates who are skilled in drug discovery but there are fears that the well is drying up. This article highlights a new course aimed at maintaining the supply.

Dr Alan Gibson, Senior Lecturer in Pharmacology, School of Biomedical Sciences, Room 2.12 Hodgkin Building, King's College London, Guys Campus, London SE1 9RT, UK. e-mail: alan.gibson@kcl.ac.uk

\title{
A BRIDGE BETWEEN ACADEMIA AND THE DRUG DISCOVERY PIPELINE
}

Two articles in the March issue of Nature Reviews Drug Discovery particularly caught the eye. On first sight, these articles seem unrelated, but on closer inspection they synergize to provide a stark warning to those who are dedicated to the design and development of new drugs. First, the Editorial highlighted the acute need to sustain the supply of graduates who are skilled in the basic disciplines underlying drug discovery, and promoted the view that the pharmaceutical industry should be proactive in fostering an understanding of the drug discovery process beyond the boundaries of the companies themselves. Second, Fredholm et al. ${ }^{1}$ described the essential role for one such basic discipline — pharmacology — and, arguing a similar line to that put forward in the Editorial, warned that the supply of highly skilled graduates in this field is under threat. This imminent skill shortage is also recognized by the relevant learned societies and, importantly, by the pharmaceutical industry itself ${ }^{2}$. So, what can be done?

In the United Kingdom, the government has appreciated the need for business and academic institutions to work more closely together. To facilitate this, it has introduced a 'third' stream of funding to universities in addition to the two established streams directed towards teaching and research. This third stream is related to the Higher Education Reach Out to Business and the Community (HEROBC) initiative, and provides universities with funds to establish closer links with industry, and thereby enhance cooperation and understanding between the two communities. Clearly, ensuring that graduates are equipped with the skills that are considered essential by the business sector is one activity that sits squarely within the HEROBC remit. However, in basic science-related disciplines, achieving this aim is not easy. Universities are charged with educating an increasing student population, while at the same time receiving fewer resources per student to carry out the job. Practical training is especially under strain given the enlarged class sizes, together with spiralling equipment and consumable costs. One answer, therefore, is to identify and target a smaller, but more focused, group of students.

At King's College London, the HEROBC funding has been used to set up a Masters programme in Drug Discovery Skills that is aimed precisely at such a target group of students (see the M.Sc. in Drug Discovery Skills web site). College academics and representatives from pharmaceutical companies within the United Kingdom got together to identify the skills that the industry regarded as vital for new recruits in the drug discovery area, and which they felt were especially under threat. Commonly identified skills were 'hands-on' practical experience (both in vitro and in vivo), experimental design and data handling, interpersonal relations and an appreciation of the multidisciplinary nature of drug design and development. The interaction between medicinal chemistry, pharmacology and pharmacokinetics was considered especially important, and an area in which improved student understanding would be highly beneficial. From these discussions, a programme has been developed in cooperation with the pharmaceutical industry, and it is hoped that the first cohort of students will be enrolled in October 2002. The shortages in each of the main skills has been addressed, with particular emphasis on the experimental techniques that are used in drug investigation - the programme contains a module on in vivo pharmacology that was specifically identified by the pharmaceutical companies as an area in which they would value having graduates with a comprehensive education.

Pharmaceutical companies have so far been sceptical about the role of Masters programmes in their recruitment strategies. However, this route allows a small group of students with a commitment to a career in the pharmaceutical industry to be identified and given an education that is tailored to the needs of industry. Continued relevance to the requirements of industry will be ensured by inclusion of industrial representatives on the Programme Advisory Board. The programme is directed towards recent graduates in the biomedical sciences, and it is of prime importance to attract high-calibre students. To this end, three pharmaceutical companies - GlaxoSmithKline, Pfizer and Pharmacia Corporation - have already committed funds to provide bursaries for students taking the programme. The involvement of the pharmaceutical industry is therefore clear. Indeed, industry has a vital role in maintaining the profile of basic disciplines such as pharmacology within universities.

The M.Sc. in Drug Discovery Skills is just one way of fuelling the skills pipeline in drug discovery. Other initiatives that address the same issue include Masters programmes, found almost exclusively within the US, which are focused on specific areas of the drug discovery process, such as bioinformatics, biotechnology and medicinal chemistry. What is clear is that the maintenance of an adequate supply of highly trained and adaptable graduates to drive forward the drug discovery process requires a concerted effort involving, among others, governments, the pharmaceutical industry and higher education institutions. The scientific media also have an important role, both in raising awareness, and in the spread of good practice.

Alan Gibson

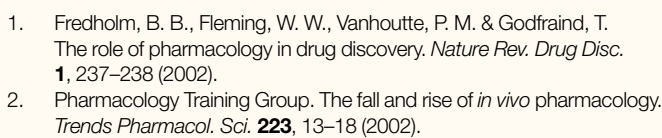

1. Fredholm, B. B., Fleming, W. W., Vanhoutte, P. M. \& Godfraind, T. The role of pharmacology in drug discovery. Nature Rev. Drug Disc. 1, 237-238 (2002).

2. Pharmacology Training Group. The fall and rise of in vivo pharmacology. Trends Pharmacol. Sci. 223, 13-18 (2002).

\section{(2) Online links}

\section{FURTHER INFORMATION}

Higher Education Reach Out to Business and the Community: http://www.hefce.ac.uk/Reachout/herobc.htm

M.Sc. in Drug Discovery Skills:

M.Sc. in Drug Discovery Skills:

http://www.kcl.ac.uk/depsta/biomedical/drugdiscovery.h 